\title{
REINVENTING INDONESIA
}

\author{
Ahmad Syatori \\ Institut Agama Islam Negeri Syekh Nurjati Cirebon \\ bang_syatori@yahoo.com
}

\begin{abstract}
ABSTRAK
Sistem politik pada negara-negara pascakolonial saat ini, yang telah dibagun atas dasar kontruksi berfikir berbasis moderisasi, demokratisasi dan liberalisasi justru memunculkan terciptanya sistem politik otoritian yang semakin digdaya. Kontruksi teoritis seharusnya menjadi semacam main reference dalam mengarahkan dan memandu perpolitikan Indonesia. Munculnya konsep negara-bangsa yang pada akhirnya mempersatukan orang-orang Indonesia dari beraneka ragam bahasa, budaya dan etnis ke dalam satu unit politik dan kesadaran akan kesamaan berkembang dalam diri masyarakat Indonesia. Identitas politik yang bernama negara-bangsa ini menginginkan terciptanya suatu bentuk kekuatan dan kekuasaan yang terpusat dan integral demi kepentingan politik bersama. Hal tersebut memunculkan falsafah yang sering dikampanyekan yaitu "Bhineka Tunggal Ika", ke-Bhinneka-an dipandang sebagai hal yang harus dilampaui untuk mencapai yang Tunggal.

Kata Kunci: Reinventing, Politik Otoritarian, Ideologi Totaliterianisme, Negara-Bangsa, Bhineka Tunggal Ika.
\end{abstract}

\begin{abstract}
The current political system in postcolonial countries, which has been built on the basis of moderation-based construction of thinking, democratization and liberalization, has led to the creation of increasingly authoritative political systems. Theoretical construction should be a kind of main reference in directing and guiding Indonesian politics. The emergence of the nation-state concept which ultimately unites Indonesians from a variety of languages, cultures and ethnicities into one political unit and awareness of similarity develops in Indonesian society. This political identity called the nation-state wants the creation of a form of power and power that is centralized and integral for the common political interests. This raises a philosophy that is often campaigned namely "Bhineka Tunggal Ika", the Unity of Diversity is seen as something that must be surpassed to achieve the Single.
\end{abstract}

Keywords: Reinventing, Authoritarian Politics, Ideology of Totalitarianism, Nation-Nation, Unity in Diversity.

\section{PENDAHULUAN}

Marilah saya mulai dengan mengajukan pertanyaan sederhana, mengapa sistem politik yang

dibangun atas dasar konstruksi

berfikir berbasis modernisasi, 
demokratisasi dan liberalisasi pada negara-negara pascakolonial, justru berakhir dengan terciptanya sistem politik otoritarian dan kian digdayanya rezim otoriter? dan pada level yang paling memprihatinkan, kian mengokohkan ideologi totaliterianisme?. Meski sederhana, pertanyaan tersebut penting untuk diajukan sebagai instrumen diagnosa atas kemungkinan terjadinya retakanretakan teoritis tentang 'Indonesia' yang telah dikonstruk oleh para teoritisi Indonesia (baca: Indonesianis) yang berbasis pada teori-teori modernitas, yang dalam banyak hal telah memberikan andil cukup besar dalam mengkonstruk sosok perpolitikan Indonesia. Dalam tradisi studi politik Indonesia, konstruksi teoritis yang diusung oleh para Indonesianis 'modernis' tersebut menjadi semacam main reference yang memandu dan mengarahkan kemana pendulum perpolitikan Indonesia itu mesti berayun. Rumusan kebijakan politik -dan ekonomi- yang akan dibentuk, baik mikro maupun makro, beserta perangkat analisis yang menyertainya, sangat ditentukan oleh sejauh mana teori-teori tersebut mampu memberikan 'resep' dan kerangka konseptual yang memadai atas realitas ke-Indonesia-an. Dalam ranah sosial-budaya, 'Indonesia' yang dikonsepsikan oleh mereka pada gilirannya menciptakan ruang imajiner bagi proses produksi dan reproduksi konsep identitas kebangsaan, pola relasi sosial kemasyarakatan, dan sebagainya. Dengan demikian, menggugat dan mempertanyakan ulang teori-teori tersebut menjadi entry point yang cukup strategis untuk mengurai fenomena kontradiktif yang diajukan oleh pertanyaan di atas.

Studi politik Indonesia, yang secara sistematis jalannya mulai dibentangkan oleh George Mc. Turnan Kahin ${ }^{1}$, pertama-tama bekerja dengan cara menciptakan ruang politik bagi Indonesia. Kecenderungan ini mengemuka terutama sebagai dampak kian menguatnya karakter geopolitik dari wacana perang dingin yang mengasumsikan keutamaan ontologis dari ruang absolut dan identitas politik sebagai kendali utama atas wilayah geografis tertentu dalam

\footnotetext{
${ }^{1}$ Benedict Anderson menganggap Kahin sebagai pionir kajian Indonesia di Amerika dan bukunya Nationalism and Revolution in Indonesia sebagai perintis. la adalah pendiri Proyek Indonesia Modern di Cornell University (Anderson 1990, hlm. 6)
} 
ruang absolut yang telah ditetapkan sebelumnya. Dalam hal ini, ruang teritori bukan hanya mengacu pada suatu gagasan geografis, tetapi pertama-tama dan yang utama merupakan suatu gagasan juridicopolitis, ruang yang secara politis dikontrol oleh suatu jenis kekuasaan tertentu. Ada keterkaitan erat antara ruang, pengetahuan dan kekuasaan. Penciptaan ruang politik yang berimplikasi pada terbentuknya konstruksi identitas politik bagi Indonesia, mengacu pada warisan sejarah kolonial yang mengindikasikan bahwa realitas keIndonesia-an muncul dari (dan di dalam) perbatasan arbitrer yang menggambarkan wilayah kontrol politik Belanda di Hindia Belanda (Kahin, 1952, hlm. 37). Ruang politik yang tercipta tersebut menjadi landaspacu bagi sekian model perumusan gagasan tentang konsep negarabangsa. Dalam konteks ini, negara Indonesia yang berdaulat memiliki hubungan linier yang kontinu dengan masyarakat-masyarakat sebelumnya dan bangsa Indonesia adalah sebuah entitas yang inheren dalam sejarah dan diangkat ke permukaan oleh kemunculan sebuah negara baru ${ }^{2}$ (Kahin, 1952, hlm. 1). Dengan kata lain, bayangan tentang negara Indonesia merupakan efek dari sentimen anti kolonial dan oleh karenanya sebagian darinya diciptakan oleh kolonialisme itu sendiri. Perbatasan Hindia Belanda yang arbitrer dan semangat anti kolonial pada akhirnya mempersatukan orang-orang Indonesia dari beragam bahasa, budaya dan etnis ke dalam satu unit politik dan kesadaran akan kesamaan cenderung berkembang dalam diri mereka (Kahin, 1952, hlm. 37).

Identitas politik yang bernama negara-bangsa itu mengandaikan terciptanya bentuk kekuatan dan kekuasaan yang terpusat dan integral demi kepentingan politik bersama. Akibatnya, keragaman -baik budaya, etnis maupun agama- tidak saja diakui keberadaannya, lebih dari itu, ia juga harus diintegrasikan dan diayomi dalam satu payung politis bernama 'persatuan dan kesatuan'. Falsafah

\footnotetext{
${ }^{2}$ Dengan kesan yang agak ekspresif, Ruth McVey membedakan 'bangsa' sebagai komitmen kolektif egalitarian yang berbasis rasa sentimen kebersamaan, dan 'negara' sebagai entitas yang dipahami bukan dalam pengertian ideal, ia bersifat hirarkis dan ditopang oleh hasrat untuk mengontrol dan terciptanya stabilitas (McVey, 1996, hlm. 11)
} 
beken yang senantiasa dikampanyekan adalah Bhinneka Tunggal Ika. Dalam hal ini, keBhinneka-an dipandang sebagai hal yang harus dilampaui untuk mencapai yang Tunggal. Pergulatan antara yang bhinneka dan yang tunggal, antara apa yang diklaim Geertz sebagai 'sentimen-sentimen primordial' dan 'revolusi integratif' ${ }^{3}$ mewarnai babak baru transformasi konsep negarabangsa. Sosok negara Indonesia yang dibayangkan memiliki otoritas yang legitimate dan integratif harus berhadapan dengan potensi konflik yang dipicu oleh keragaman budaya, etnis dan agama akibat dari fakta bahwa loyalitas dan perasaan solidaritas yang terbangun itu tersebar pada setiap kelompok komunal dan kuasi komunal yang berjumlah banyak. Pada level pertama, terdapat suatu pemisahan yang tajam dan ditekankan oleh nasionalisme Indonesia antara orang-orang Indonesia di satu sisi dan orang-orang Cina, Arab dan Eropa di sisi yang

${ }^{3}$ Geertz meyakini bahwa masalah serius yang dihadapi oleh negara-negara baru pascakolonial dalam menciptakan identitas politik dan revolusi integralnya adalah kerentanannya terhadap sentimen-sentimen yang dipicu oleh rasa primordialisme. Sentimen primordial dialamatkan oleh Gerrtz sebagai identitas tradisional yang meliputi adat istiadat, ras, etnis, dan agama (Geertz, 1973, hlm. 83) lain. Pada level kedua, komunitas bangsa Indonesia sendiri terbagi menjadi sekitar 366 kelompok etnis yang memiliki identitas tradisional dan mencakup setidaknya sepuluh kelompok besar dengan populasi lebih dari satu juta orang (Feith, 1962, hlm. 27).

\section{PEMBAHASAN}

Sistem Birokrasi Modern, Logika Modernisasi dan Diskursus Developmentalisme

Transformasi konsep negarabangsa Indonesia menjadi sebuah kekuatan politik yang menjunjung tinggi nilai-nilai persatuan dan kesatuan serta integritas nasional, dalam sistem dan praktek tata-kelola pemerintahannya, dikawal dan disokong oleh sebuah sistem birokrasi warisan sejarah kolonial bernama beamtenstaat. Pada mulanya, beamtenstaat merupakan strategi pemerintah Hindia Belanda dalam rangka menguasai dan mengontrol daerah koloninya yang telah memiliki tradisi politik dan pemerintahan ala kerajaan-kerajaan nusantara yang membentang sejak zaman pra-Hindu, Hindu dan Islam. Dalam pengertian yang lebih luas, beamtenstaat sesungguhnya adalah sebuah ruang 
Jurnal Yaqzhan : Analisis Filsafat, Agama dan Kemanusiaan|

Vol 5, No 1, Juni 2019

dialog kebudayaan antara budaya nusantara yang berorientasi pada sistem nilai magis-religius dengan budaya Barat yang rasional-sekuler (Kayam, 1989, hlm. 14). Sebagai sebuah model style of governance, beamtenstaat mengandaikan sebuah sistem pemerintahan yang apolitik yang terutama mengandalkan dinamikanya pada birokrasi dan tidak pada kekuatan politik yang hidup dalam masyarakat. Sistem birokrasi yang dibangun bersifat hirarkis dan berjenjang dengan memanfaatkan elite 'priyayi', sebagai kelompok keturunan bangsawan, yang disulap menjadi semacam 'korps' anggota birokrasi. Sebagai sebuah sistem birokrasi hibrid, beamtenstaat tidak sepenuhnya bersifat rasional-hirarkis seperti model birokrasi Barat, tapi ia juga masih mewarisi sistem patrimonial warisan tradisi Jawa.

Dalam menjalankan mekanisme kekuasaannya, konsep nation-state yang berbasis nilai-nilai 'luhur' integritas nasional dan ditopang oleh sistem birokrasi modern, mendapatkan justifikasi dengan beroperasinya logika modernisasi dan developmentalisme atau pembangunanisme. Logika modernisasi, terutama banyak diilhami oleh asumsi-asumsi dasar teori evolusi yang memandang bahwa sejarah perkembangan manusia dan masyarakat berjalan linier dari masyarakat primitif menuju masyarakat modern atau maju (Comte, 1964, hlm 14) . Perubahan menuju bentuk masyarakat modern diyakini merupakan sesuatu yang tidak dapat dihindarkan. Oleh karena masyarakat modern merupakan bentuk masyarakat yang dicitacitakan, yang mengandung semua unsur yang disebut 'baik' dan 'sempurna', maka didalamnya terdapat apa yang oleh teori evolusi disebut sebagai kemajuan, kemanusiaan dan pemberadaban. Modernisasi dipandang sebagai sebuah proses transformasi yang sistematis. Dalam rangka mencapai status modern, struktur nilai-nilai tradisional secara total harus diubah dengan seperangkat struktur dan nilainilai modern. Akibatnya, modernisasi menghasilkan proses homogenisasi, dimana proses transformasi akan menghasilkan model masyarakat dan struktur sosial yang seragam. Asumsiasumsi tersebut semakin menemukan justifikasi absolutnya dengan 
berkembangnya paradigma struktural fungsional $^{4}$ dalam ilmu sosial. Paradigma ini mendasarkan basis teoritisnya dengan asumsi-asumsi dasar berikut: a) Masyarakat harus dilihat sebagai suatu sistem yang kompleks, terdiri dari bagian-bagian yang saling berhubungan dan saling tergantung dan setiap bagian tersebut berpengaruh secara signifikan terhadap bagian-bagian lainnya, b) Setiap bagian dari sebuah masyarakat eksis karena bagian tersebut memiliki fungsi penting dalam memelihara eksistensi dan stabilitas masyarakat secara keseluruhan, karena itu, eksistensi satu bagian tertentu dari masyarakat dapat diterangkan apabila fungsinya bagi masyarakat sebagai keseluruhan dapat teridentifikasi, c) Semua masyarakat mempunyai mekanisme untuk mengintegrasikan diri, sekalipun integrasi sosial tidak pernah tercapai secara sempurna, namun sistem sosial akan senantiasa

\footnotetext{
${ }^{4}$ Paradigma ini untuk kali pertama diintrodusir oleh Talcott Parsons dengan teorinya AGIL (Adaptation to the environment, Goal attainment, Integration and Latency). Kaitannya dengan tata Negara dan pemerintahan, konsep tersebut diterjemahkan sebagai lembaga ekonomi menjalankan fungsi adaptasi lingkungan, pemerintah bertugas untuk pencapaian tujuan umum, lembaga hokum dan agama menjalankan fungsi integrasi dan keluarga dan lembaga pendidikan berfungsi sebagai usaha pemeliharaan.
}

berproses ke arah itu, d) Perubahan dalam sistem sosial umumnya terjadi secara gradual, melalui proses penyesuaian, dan tidak terjadi secara revolusioner, e) Faktor terpenting yang mengintegrasikan masyarakat adalah adanya kesepakatan di antara para anggotanya terhadap nilai-nilai kemasyarakatan tertentu, f) Masyarakat cenderung mengarah kepada suatu keadaan ekuilibrium atau homoeostatis (Maliki, 2003, hlm. 45). Seiring perkembangan paradigma modernisasi dalam ilmu sosial, logika modernisasi juga berkembang dalam ranah teori-teori ekonomi ala Rostow $^{5}$ yang menekankan pada proses pertumbuhan ekonomi. Pertumbuhan tersebut bertahap mulai dari tahap masyarakat tradisional dan berakhir pada tahap masyarakat dengan konsumsi massa tinggi. Pada perkembangannya, teori Rostow berasumsi bahwa jika sebuah negara hendak mencapai pertumbuhan ekonomi yang otonom dan berkelanjutan, maka negara tersebut harus memiliki struktur ekonomi tertentu. Yakni negara tersebut harus mampu melakukan mobilisasi seluruh kemampuan modal dan sumberdaya

\footnotetext{
${ }^{5}$ Rostow mengintrodusir teorinya dalam buku The Stages of Economic Growth.
} 
alamnya sehingga mampu mencapai tingkat investasi produktif sebesar $10 \%$ dari pendapatan nasionalnya (Suwarsono dan Alvin, 2006, hlm. 16).

Dalam bingkai logika seperti ini Indonesia lalu dibayangkan sebagai negara yang sedang mengalami proses perkembangan itu. Indonesia sedang berada pada proses menuju 'kemajuan' dan karenanya seluruh infrastruktur yang menopangnya, baik ekonomi, politik, sosial maupun budaya, mesti diarahkan ke sana. Pembangunan pada semua sektor tersebut, terutama sektor ekonomi-politik, menjadi pilihan yang cukup rasional dalam rangka pencapaian cita-cita 'kemajuan' itu. Modernisasi pertamatama bertumpu pada upaya pembangunan ekonomi yang berkesinambungan. Pembangunan ekonomi dapat berjalan efektif jika ditopang dengan stabilitas politik dan keamanan nasional. Tugas pokok aparatus negara selanjutnya adalah menjaga stabilitas tersebut, dengan cara apapun. Setiap tindakan yang mengarah kepada ancaman 'instabilitas' dan gangguan keamanan akan berhadapan dengan kekuatan represif negara. Kolaborasi logikasi modernisasi dan ide percepatan pembangunan menuju arah cita-cita kemajuan melahirnya sebuah 'ideologi' politik bernama pembangunanisme. Secara historisgeneologis, ide pembangunanisme sebenarnya telah berakar cukup kuat dari nilai-nilai kapitalisme yang tumbuh sejak era ekonomi merkantilis mendominasi sistem perdagangan di eropa pada abad ke-15. Sebagai style of governance, pembangunanisme menitikberatkan pada maksimalisasi produktifitas ekonomi dan karenanya perlu diupayakan penyempitan ruang sosial dan konflik sosial. Untuk itu dibutuhkan aparatur negara dengan desain kelembagaan yang dapat menjamin terciptanya mekanisme yang mampu meniadakan konflik ideologis, mengutamakan konsensus dan ketertiban, serta membatasi secara minimal peran serta politik masyarakat. Pembangunanisme merupakan konsep deterministik yang meletakkan pembangunan dalam arti ekonomi, material, dan fisik, tanpa mempertimbangkan ruang sosial, karakter, nilai dan budaya yang hidup dan berkembang dalam masyarakat. Dalam realitas politik Indonesia, 
seperti kita saksikan bersama-sama, 'ideologi' politik pembangunanisme telah memicu munculnya rezim pemerintahan yang represif otoritarian.

\section{Diskursus 'Kekuasaan'}

yang

\section{Terabaikan}

Dari sekian deretan diskursus politik Indonesia yang memadati halaman demi halaman buku-buku Indonesian studies, kesan umum yang segera tertangkap adalah bahwa ia mengabaikan entitas lain di luar negara, yakni masyarakat sipil. Pembangunanisme yang menjadi metanarasi dalam diskursus politik Orde Baru dibentangkan dengan perspektif sempit yang menyamakan dan mengukurnya dalam idiom-idiom ekonomi. Pembangunan kerap kali dipahami dalam bingkai mode narasi produksi atau narasi liberal yang menghubungkan konsep-konsep pembangunan ekonomi, kebebasan dan demokratisasi. Namun demikian, analisis tentang berbagai praktek dimana masyarakat sipil diproduksi dalam diskursus ekonomi tetap terabaikan. Akibatnya, subyek Indonesia dipahami sebagai sesuatu yang given dan statis, pembangunan mengubah orang Indonesia 'hanya' untuk mengkonsumsi dan pola-pola konsumsi mereka. Lebih jauh, karena 'ekonomi' tidak diperlakukan sebagai suatu wilayah diskursif atau cara $\mathrm{p}(\mathrm{m})$ emerintah, maka karakteristik subyek Indonesia tampak tidak mengalami perubahan. Dalam konteks ini, menjadi Indonesia berarti mentransendenkan diskursus pembangunan ekonomi. Pembangunan bisa mengancam identitas tradisional dan mendorong terbentuknya identitas baru, namun ia tidak dilihat sebagai lokasi dimana identitas tersebut diproduksi. Pembangunan mestinya dipahami sebagai entitas yang mengasumsikan bahwa kekuasaan yang dihasilkannya merupakan kekuatan produktif dan subyek individu menjadi sasaran utamanya. Kendati keseluruhan diskursus pembangunan tidak memiliki koherensi, tetapi ia didasarkan pada penggunaan berbagai tekhnik dan tekhnologi di berbagai institusi, baik institusi hukuman maupun bukan, termasuk sekolah, kelompok kepentingan dan birokrasi. Jika cara untuk memenuhi tujuan pembangunan bersifat imanen dalam masyarakat, maka teknologi diri 
Jurnal Yaqzhan : Analisis Filsafat, Agama dan Kemanusiaan|

Vol 5, No 1, Juni 2019

merupakan elemen penting dalam memahami operasi kekuasaan yang berlaku di Indonesia pada saat ini.

\section{Absennya}

diskurus

masyarakat sipil dalam studi politik Indonesia, mengindikasikan pengakomodasian yang timpang tentang diskursus kekuasaan di dalamnya. Kualitas kekuasaan yang dibahas di dalamnya lebih merupakan asumsi dari pada argumentasi. Kekuasaan dipandang melulu sebagai kekuatan represif dan prohibit yang digunakan oleh institusi negara, khususnya Orde Baru, untuk menundukkan orang lain pada kehendak rezim. Berbagai kajian politik selama Orde Baru mencirikan kekuasaan sebagai kekuatan militer yang negatif, tercela dan merupakan kewenangan negara. Pandangan ini meyakini bahwa penggunaan kekerasan oleh negara (yang dalam bentuk yang paling ekstrim terwujud dalam pembunuhan warga negara) sebagai ekpresi tertinggi dari kekuasaan. Akibatnya, kekuasaan lebih dipandang sebagai sesuatu yang dimiliki oleh negara dari pada dipahami sebagai jaringan strategis dan taktis, yang selalu berada dalam proses pemerolehan dan senantiasa menghadapi perlawanan dari mereka yang dikuasainya. Produksi teori kekuasaan yang militeristik, tercela dan berbasis negara memunculkan semacam paradoks dalam diskursus politik Indonesia. Meskipun subyek yang berpengetahuan menjadi pusat otoritas diskursus politik Indonesia, namun asumsi teori kekuasaannya cenderung menghapuskan subyek politik karena ia dikonstruksi dalam binaritas kuat/lemah. Dengan memperlakukan kekuasaan sebagai sesuatu yang negatif dan represif secara universal, subyek dibatasi atau bahkan dihancurkan oleh operasi kekuasaan dan dibungkam olehnya. Tiadanya konsep agency menunjukkan posisi subyek dimana subyek individu merasakan bobot kekuasaan, tetapi -jika yidak dihancurkan- secara esensial tetap tidak berubah karenanya. Dengan kata lain, ketika kekuasaan dijalankan, penyusutan identitas dan pembungkaman merupakan hasil yang tak terelakkan. Kekuasaan pun lalu dipahami memiliki efek yang homogen, tidak problematik dan universal.

Lebih jauh, produksi teori kekuasaan seperti itu hanya 
menyisakan sedikit ruang untuk mempertimbangkan cara-cara yang dipergunakan untuk membentuk subyek Indonesia kontemporer sebagai 'subyek pembangunan'. Penjelasan argumentatif yang dilontarkannya tidak banyak membicarakan tentang cara-cara yang dipergunakan untuk menyusun ulang tubuh individu dengan strategi dan praktek pembangunan tertentu, atau cara-cara yang dipergunakan untuk membuat masyarakat menjadi (lebih) produktif, patuh dan tertib. Padahal, sebagaimana Foucault, 'pemerintah' memang semestinya dipahami bukan hanya sekedar struktur politik atau manajemen negara, tetapi lebih dari itu, ia dipahami sebagai serangkaian strategi dan taktik yang diarahkan pada kontrol prilaku individu atau kelompok dan bentuk aksi yang mengatur apa yang boleh dan tidak boleh dilakukan oleh orang lain (Foucault, 1982, hlm. 221).

\section{On Governmentality}

Sudah saatnya studi politik Indonesia kontemporer memperlakukan diskursus kekuasaan sebagai sesuatu yang berbentuk heterogen dan merupakan kekuatan produktif dalam diskursus dan lokasi tertentu. Kekuasaan tidak lagi dipahami sebagai 'hanya' milik negara dan tidak begitu saja dipraktekkan pada masyarakat yang berada di bawah pengawasannya. Ia lebih dipahami sebagai serangkaian strategi, program, kalkulasi, teknik, perangkat, dokumen dan prosedur melalui mana otoritas mengejewantah dan menciptakan pengaruh pada ambisi memerintah. Dengan kata lain, ia lebih dari sekedar kapasitas bertindak yang hanya dimiliki oleh institusi negara. Ia dipahami sebagai penggunaan dan penciptaan teknologi untuk mengatur prilaku. 'Pemerintah' memiliki kapasitas untuk mengetahui 'kebenaran' dari domain tertentu, sekaligus memiliki kapasitas untuk menetapkan kebenaran itu sedemikian rupa sehingga domain bersangkutan mudah dievaluasi, dikalkulasi dan diintervensi. Dalam pengertian ini 'relitas' adalah efek dari diskursus tertentu dari pemerintah. Semua individu yang menjadi sasaran dari diskursus pemerintah, diciptakan dalam diskursus itu. Dengan demikian, identitas terkait dengan domain di mana individu di perintah. Dengan cara demikian, kekuasaan 
Jurnal Yaqzhan : Analisis Filsafat, Agama dan Kemanusiaan|

Vol 5, No 1, Juni 2019

dipahami dengan cukup lebih memadai dalam konteks diskursus ' $\mathrm{p}(\mathrm{m})$ emerintah', on governmentality ${ }^{6}$ (Philpott, 2000, hlm. 150). Imbasnya, negara dan masyarakat sipil tidak bisa lagi dipahami sebagai domain yang otonom, atau bahkan antagonistik. Hal ini, tentu saja merupakan pergeseran yang cukup signifikan dari model dominan dalam studi poltik Indonesia yang menganggap bahwa hubungan antara negara dan masyarakat sipil sangat birokratis dan karenanya negara memiliki kepentingan yang terpisah dari kepentingan masyarakat sipil, yang coba diraihnya dengan membatasi atau mengontrol artikulasi yang tidak sesuai dengan kepentingan negara.

Governmentality memandang bahwa domain pemerintah sebenarnya terdapat dalam berbagai diskursus yang diciptakan untuk memerintah. Pertanyaan-pertanyaan yang menyangkut legitimasi kekuasaan digantikan oleh perhatian pada teknik dan rasionalitas kekuasaan, atau dengan kata lain oleh pertanyaanpertanyan praktis yang menyoal tentang bagimana memandu perilaku

\footnotetext{
${ }^{6}$ Konsep ini diintrodusir oleh Foucault melalui serangkaian kuliah yang diberikannya antara tahun 1978-1979.
}

negara dan perilaku masyarakat yang diklaim oleh negara berada dibawah kekuasaannya. Governmentality tidak memahami rasionalitas negara dalam pengertian negatif, tetapi positif dan rasionalitas tersebut bersifat imanen. Governmentality memandang bahwa pemerintah(an) adalah suatu aktivitas kompleks yang memiliki tujuan yang secara intrinsik terkait dengan berbagai persoalan di sekitarnya, berbagai kesalahan yang coba diralatnya, penyakit yang coba disembuhkannya. Dalam pandangan ini, ada tiga elemen dalam rasionalitas politik yang mengatasi berbagai persoalan yang diidentifikasikasi oleh pemerintah(an) (Philpott, 2000, hlm. 172). Pertama, rasionalitas politik memiliki bentuk moral, dimana kekuasaan dan kewajiban penguasa dielaborasi, distribusi kewajiban di antara para penguasa dijelaskan dan di mana cita-cita serta prinsip yang harus dipenuhi oleh pemerintah dipertimbangkan. Kedua, rasionalitas politik itu memiliki karakter epistemologis dimana ia dielaborasi dalam kaitannya dengan hakikat obyek yang dikuasai, biasanya dengan menggunakan penjelasan tentang orang-orang yang menjadi sasaran 


\section{Ahmad Syatori | Reinventing Indonesia}

praaktek pemerintah(an). Ketiga, otoritarianisme ke demokrasi sebagai rasionalitas politik itu diartikulasikan suatu hal yang tergantung pada dalam suatu idiom tertentu, yang bisa tumbuhnya masyarakat sipil dalam dimengerti sebagai sejenis mesin bentuk kelompok-kelompok intelektual untuk menjadikan realitas sebagai suatu hal yang masuk akal dengan sedemikian rupa sehingga ia bisa tunduk pada pertimbangan politik. Governmentality tidak memahami negara dan masyarakat sipil dalam pengertian oposisi biner, yang selalu bertentangan dan masingmasing berusaha melemahkan pengaruh yang lain. Governmentality memandang bahwa kekuasaan bukanlah persoalan menerapkan belenggu pada warga negara dengan tujuan membuat mereka mampu mengemban bentuk kebebasan yang terkontrol. Otonomi individu bukanlah antitesis dari kekuasaan politik, melainkan merupakan istilah kunci dalam praktek kekuasaan politik, karena sebagian besar individu bukan hanya menjadi subyek kekuasaan tetapi juga berperan menjalankan operasi kekuasaan itu. Dengan cara demikian governmentality membedakan dirinya dengan diskursus 'transisi demokrasi' yang banyak memperbincangkan tema seputar transisi dari kepentingan. Hal ini menunjukkan bahwa demokrasi hanya akan muncul apabila masyarakat mengembangkan kemampuannya dalam mengartikulasikan kepentingan yang berbeda dan kepentingan para aparatus negara. Namun demikian, perbedaan kepentingan itu masih mensyaratkan 'ruang' untuk mengartikulasikannya dan ruang ini dianggap menjadi ukuran yang tepat dalam relasi negara/ masyarakat sipil. Dengan kata lain, demokrasi identik dengan ketiadaan negara dalam masyarakat sipil. Dalam diskursus 'transisi demokrasi', perbedaan tajam antara demokrasi dan otoritarianisme dibatasi pada pemahaman tentang cara-cara untuk menjalankan pemerintahan dalam masyarakat yang tidak demokratis. Korelasi antara demokrasi, kebebasan, dan rasionalitas versus otoritarianisme, dominasi dan irrasionalitas, menutup mata terhadap kemungkinan munculnya berbagai strategi kepemerintahan yang produktif dan beraneka ragam yang berlaku dalam 
Jurnal Yaqzhan : Analisis Filsafat, Agama dan Kemanusiaan|

Vol 5, No 1, Juni 2019

masyarakat otoritarian.

\section{DAFTAR PUSTAKA}

Anderson, B.R.O.G. (1990). Language and Power: Exploring Political Cultures in Indonesia. Ithaca: Cornell University Press.

Comte, A. (1964). "The Progress of Civilization through Three Stages," dalam Eva Etzioni dan Amitai Etzioni (eds.), Social Change, New York: Basic Books.

Feith, H. (1962). The Decline of Constitutional Democracy in Indonesia. Ithaca: Cornell University Press.

Foucault, M. (1982). "Afterword: The Subject and Power". Dalam H.L Dreyfus dan P Rabinow. Michel Foucault: Beyond Structuralism and Hermeneutics. Brighton: The Harvester Press.

Geertz, C. (1973). The Interpretation of Cultures. New York:Basic Book

Kahin, G.McT. (1952) Nationalism and Revolution in Indonesia. Ithaca: Cornell University Press.

Kayam, U. (1989). Transformasi Budaya Kita, Pidato Pengukuhan Jabatan Guru Besar pada Fakultas Sastra Universitas Gadjah Mada, Diucapkan di Muka Rapat Senat Terbuka Universitas Gadjah Mada pada tanggal 19 Mei 1989 di Yogyakarta.

McVey, R. (1996). Making Indonesia: Eassay on Modern Indonesia in Honor of George McT Kahin (eds.) by Daniel S. Lev and Ruth McVey. Cornell: Cornell University Press.

Maliki, Z. (2003). Narasi Agung: Tiga Teori Sosial Hegemoni.
Surabaya: LPAM

Philpott, S. (2000). Rethingking Indonesia:Postcolonial Theory, Authoritarianism and Identity. London: MacMillan Press.

Suwarsono \& alvin Y. SO. (2006). Perubahan Sosial dan Pembangunan. Jakarta: LP3ES. 